\title{
A Meta-Analysis of Bone Mineral Density in Collegiate Female Athletes
}

\author{
Armin Arasheben, MD, Kathleen A. Barzee, MPH, and Christopher P. Morley, PhD
}

Purpose: In a number of small studies focused on one or two sports, exercise and competitive level has been observed to favor attainment of higher bone mineral density (BMD) in otherwise healthy athletes. We analyzed merged data from 10 studies to determine the effects of competitive level on upper extremity BMD in female athletes across multiple sports.

Methods: This study is a meta-analysis of 10 articles reporting results of similar case-control and cross-sectional studies of BMD in female athletes and nonathletes reporting an effect of athletic participation level. Upper extremity BMD was modeled as an outcome of the level of athleticism using a categorical weighted least squares model and controlling for upper-body impact, age, and body mass index.

Results: Upper extremity BMD significantly increased for each level of participation $(\beta=0.140 ; 95 \%$ CI, 0.047-0.234), Age and body mass index approached significance but the level of upper extremity impact was not significant in the final model.

Conclusions: Clinicians may see iteratively greater BMD in female patients who compete at increasingly intense athletic levels, with elite athletes having much higher BMD than other patients who are either active or not. Further research is needed to identify direction and causality of the relationship between competitive level and BMD. (J Am Board Fam Med 2011;24:728-734.)

Keywords: Metabolic, Orthopedics, Sports Medicine, Women's Health

Bone mineral density (BMD) is influenced by genetic, biologic, and environmental factors, including genetics, smoking history, calcium and vitamin D levels, hormonal changes, sun exposure, and physical exercise. ${ }^{1,2}$ Of these factors, exercise is often overlooked as an important factor for regulating BMD. Exercise-related bone stress has been shown to be effective in maintaining ${ }^{1,3}$ and increasing $^{2} \mathrm{BMD}$, and the magnitude of bone-loading

This article was externally peer reviewed.

Submitted 30 November 2010; revised 12 April 2011; accepted 18 April 2011.

From the Family Medicine Residency, St. Joseph's Hospital Health Center, Syracuse, NY (AA); the Department of Family Medicine (KAB, CPM), the Department of Public Health and Preventive Medicine, and the Department of Psychiatry (CPM), State University of New York Upstate Medical University, Syracuse, NY (KAB).

Funding: This project was partially funded by the Health Resources and Services Administration, Academic Administrative Units in Primary Care grants D54HP0542 and D5AHP19904.

Conflict of interest: none declared.

Corresponding author: Christopher P. Morley, Department of Family Medicine, State University of New York Upstate Medical University, 750 E. Adams Street, MIMC 200, Syracuse, NY 13210 (E-mail: morleycp@upstate.edu). seems to increase in parallel with increasing exercise intensity. ${ }^{4,5}$ Bone-loading exercises seem to have the greatest impact on bone accretion rates $^{2,4-6}$ compared with endurance exercises. Similarly, short spurts of bone-loading activity have a more significant increase in BMD compared with long, moderate, repetitive stress. ${ }^{7-10}$ Upper-extremity BMD values are generally higher in athletes who sustain repetitive bone-loading forces compared with sedentary controls. ${ }^{11-14}$ Similarly, they are naturally exposed to higher bone-loading stress than controls. ${ }^{6}$ The minimal weight-bearing activity that produces an osteogenic effect is unknown. Still, athletes exhibiting higher bone impact usually show higher BMD values. As a result, $\mathrm{BMD}$ values in such athletes are generally higher unless notable discrepancies such as the female athlete triad ${ }^{15,16}$ and other risk factors are seen for a prolonged period.

Female athletes can experience sex-related negative influences on bone accretion. The spectrum of low energy availability, amenorrhea, and osteoporosis, either alone or in combination, are regarded as significant health risks for female 
athletes and are medically referred to as "the female triad." ${ }^{15,16}$ Female athletes who participate in gymnastics, track, diving, dance, and synchronized swimming are affected most frequently. ${ }^{1}$ Supporting this idea, women who exercise and maintain normal menstrual cycles seem to have higher BMD than amenorrheic women. ${ }^{17}$ This is an important variable in risk stratification of active female athletes and their propensity for fractures.

The quantification of exercise intensity in terms of bone loading is difficult. However, there have been a number of relatively small studies of BMD in female athletes conducted over the past several decades, which tend to show that exercise at higher intensity levels is associated with greater bone accretion, and hence higher BMD. To investigate this effect across different sports, we conducted a meta-analysis of 10 articles concerned with upperextremity BMD in female athletes. The purpose of this study was to compare different levels of athletic competitive participation and to evaluate the affect of participation in various sports on bone accretion compared with habitual exercisers and sedentary controls. Focusing on BMD in one body site (the upper extremity) allowed for a homogenous analytic sample.

\section{Methods}

The current meta-analysis was performed using a subset of articles collected as part of a systematic review of the literature about BMD in female athletes, which was initiated by a family medicine resident (AA). Although there is no published protocol for this ongoing process, the review procedures generally followed Preferred Reporting Items for Systematic Reviews and Meta-Analyses guidelines. ${ }^{18} \mathrm{~A}$ summary of the search and selection process for this project is depicted in Figure 1.

\section{Literature Search}

We retrieved 156 results from a mid-2009 search of the PubMed database using the string:

Figure 1. Selection steps for peer-reviewed publications included in the meta-analysis (format adapted from Moher et al. ${ }^{18}$ ).
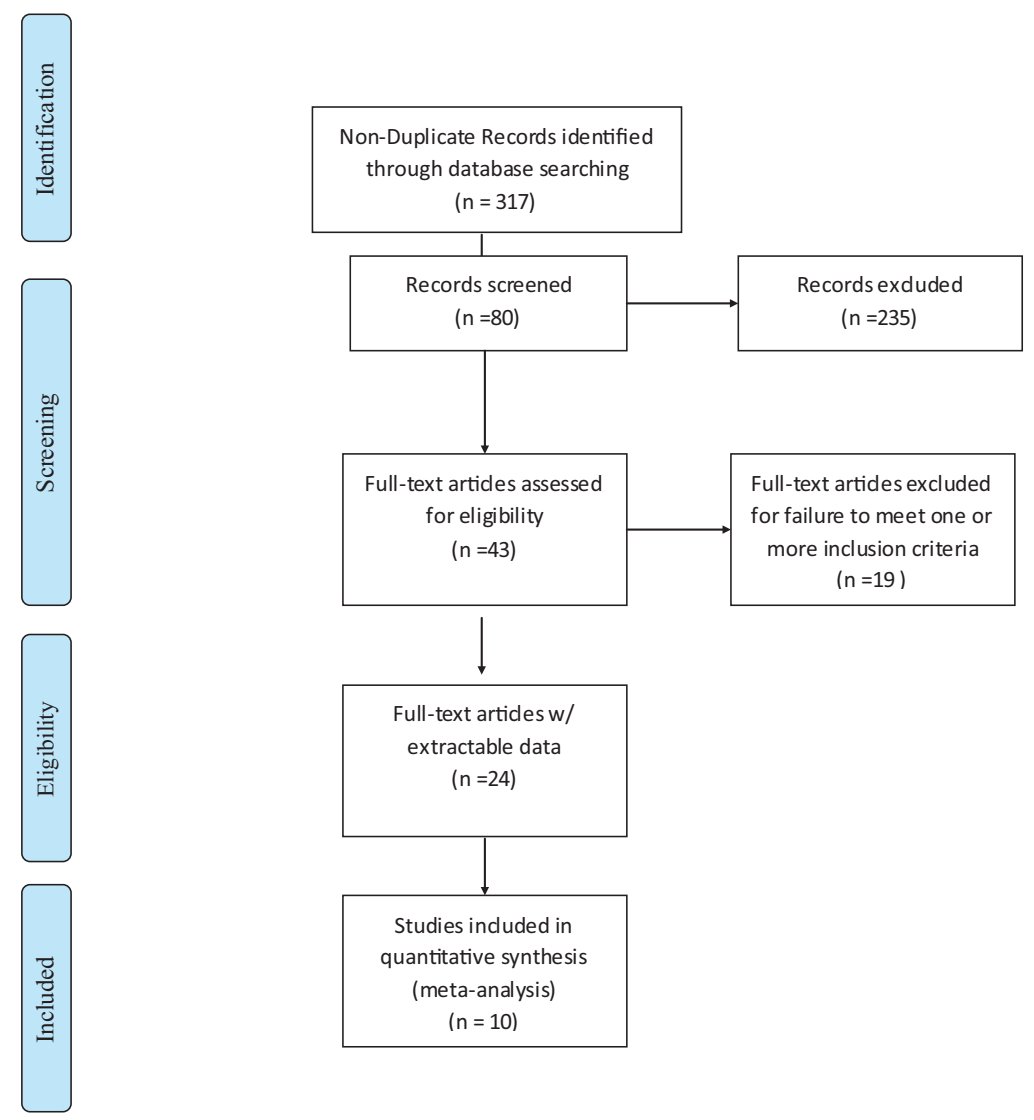
(“Sports”[Majr] AND "Female”[Mesh]) AND "Absorptiometry, Photon"[Mesh].

A second search was performed in early 2010 with the expanded string:

("Sports"[MeSH Terms] OR "athletes" $[\mathrm{MeSH}$ Terms] OR Sports Medicine[mh]) AND ((“women" [MeSH Terms] OR "female" [MeSH Terms]) OR "female" [MeSH Terms]) AND "absorptiometry, photon"[MeSH Terms]).

The second search yielded an additional 70 results after duplicates were removed. We supplemented these methods by manually searching the reference lists of the articles chosen for extraction and by searching the Cochrane Database using the terms BMD, bone mineral, bone, and/or athlete. These two additional searches resulted in 64 and 25 publications, respectively, for a total of 315 results. Periodic re-entry of the initial PubMed search strings showed two additional studies since the initial search, for a total of 317 results as of November 29,2010 . One article that potentially would have been included was deselected because it focused on a prepubertal stage of growth. ${ }^{19}$

\section{Study Selection}

We selected English-only articles that reported BMD measurement data from studies of female athlete subjects, though we did not exclude studies with male subjects. We selected studies of athletes that had no medical issues; if a study had some athletes with amenorrhea or who were taking supplements, we included that study only if supplementation or menstruation status was accounted for as a variable in the study design. The BMD data had to include upper-arm measurements and could also include measures taken at other body sites. Use of upper-extremity measurements allowed for uniform analysis. During the period in which a study was conducted, and for at least 6 months before its start, subjects from at least one female group had to be participating at a competitive or elite level in one or more common sports (eg, basketball, running, gymnastics). Competitive-level participation was defined as engaging in the sport for at least one season and on a frequent basis in a structured competitive environment (eg, high school varsity teams, collegiate divisions I, II, or III) or in independent training sessions (eg, independent Olympic competitors) for a significant number of hours per week. Studies that did not include data for the number of hours per week that the subjects engaged in the sport were excluded.

We classified the athlete study groups by the sports' impact level and by the intensity with which the groups' subjects engaged in their sport. For the former, we used the same methodology as Torstveit and Sundgot-Borgen ${ }^{20}$ to designate sports as low, medium, or high impact. For the latter, we used the sports by the US NCAA ${ }^{21}$ class listed in the studies (or the equivalent, based on the described training regimen, for the two non-US studies). Because the activity level of the nonathlete control groups ranged from exercising for $<1$ hour per week ${ }^{14,22}$ to nearly11 hours per week, ${ }^{23}$ we placed nonathlete control groups into either "active" or "nonactive" categories.

\section{Data Extraction}

Two authors (AA and $\mathrm{KB}$ ) reviewed the initial 317 search results and agreed to exclude 229 articles based on their titles and six articles because they were not available in English. Both of these authors reviewed the abstracts of the remaining 80 articles and agreed that 43 articles should be fully reviewed before inclusion could be determined. After agreeing that 19 of the 43 fully reviewed articles did not meet all of the inclusion criteria, one author extracted data from the remaining 24 articles (KB) while the second checked the extracted data (AA). After review of the full set of extracted data, data from 10 of the 24 articles were determined to be sufficiently compatible and complete for inclusion in the meta-analysis. ${ }^{14,22-31}$ Specifically, all 10 studies gave the average BMD measurement and standard deviation for subject groups" "total dominant arm." Thirteen of the other 14 articles for which data had been extracted were excluded because they provided data for BMD measured at other parts of the arm (eg, radius, humerus). The 14th article used the total dominant arm measure but was excluded because the standard deviation for the study groups' average reading was not provided. BMD was measured using Lunar-manufactured equipment in five of the studies, ${ }^{14,23,24,30,31}$ whereas Hologic-manufactured equipment was used in the other five studies. $22,25,27-29$

\section{Analysis}

Using upper-extremity BMD as the outcome measure, we constructed a matrix of study results from 
the 10 articles selected into meta-analysis. Subjects were grouped into four categories: elite athletes, nonelite competitive athletes, active controls, and nonactive controls. Elite subjects were defined as competing at the US NCAA Division 1 level or equivalent ( $\mathrm{n}=192)$; nonelite competitive athletes competed at the NCAA II/III or equivalent level ( $\mathrm{n}=214)$; active controls were noncompetitive subjects who self-reported exercise at moderate levels $(\mathrm{n}=172)$; and nonactive controls (or those with undefined activity) reported no regular exercise $(\mathrm{n}=73)$.

Outcomes were calculated in SPSS software (version 18; SPSS, Inc., Chicago, IL) using weighted linear regression, estimating effect size as the $\beta$ coefficient of weight-bearing intensity and class of competitive competition and controlling for available confounders (mean body mass index, age, and body-fat content) in each group of each study. A weighting variable was calculated in an initial linear regression to adjust for the number of subjects in each study group. Weight-bearing intensity was coded as a binary variable, with study groups engaged in sports with high-intensity impact on upper extremities (basketball, boxing, gymnastics, handball, and volleyball) versus sports with limited upper-extremity impact intensity (ice skating, soccer) and controls (high impact $=1$, low or no impact $=0$ ). Elite athleticism and intensity were analyzed separately and together; in addition, other definitions of athleticism were also analyzed, grouping competitive athletes together against active and nonactive controls and grouping all active subject groups together against nonactive controls.

\section{Results}

The studies included in the meta-analysis, and summarized in Table 1, were published between 1993 and 2008. Six of the 10 were conducted in the United States, ${ }^{14,22,27,28,30,31}$ with one each done in Spain, ${ }^{29}$ Canada, ${ }^{23}$ the United Kingdom, ${ }^{25}$ and Australia. ${ }^{24}$ None of the studies included any male subjects. The average age of the study subjects ranged from $14^{29}$ to 26.7 years, ${ }^{23}$ and the overall mean age across studies was 19.8 years.

All studies used either a case-control or crosssectional design and compared the BMD of one or more subject groups involved in different sports against less physically active ("nonathlete") control groups. Most of the sports in the studies were high impact (basketball, soccer, gymnastics, tennis, boxing, handball, ice skating, netball, and rugby). Five of the studies included sports that do not theoretically result in high upper-extremity impact (swimming, cycling, and running). The number of subjects in the study groups ranged from six in the smallest group to 27 in the largest.

The results of the regression analysis are displayed in Table 2. Upper-extremity BMD significantly increased for athletes competing at an elite (Division I) NCAA level ( $\beta=0.140 ; 95 \% \mathrm{CI}$, $0.047-0.234)$. The level of upper-extremity impact was not significant in any model, although its inclusion in a model with the variable indicating participation in elite athletics dropped the significance level of elite athleticism below statistical significance.

\section{Discussion}

There are significant differences between observed BMD in athletes compared with nonathletes and between the levels of intensity of the competitive activity. As the competitive level increased, the observed BMD increased. With each increase in activity level, BMD seemed to increase by about 0.05 $\mathrm{g} / \mathrm{cm}^{-2}$; the difference between the groups of elite (NCAA Division I) athletes and all others was larger by about $0.123 \mathrm{~g} / \mathrm{cm}^{-2}$.

Conversely, the intensity of upper-extremity impact, as coded in this study, seemed to have had a minimal impact, if any. This may suggest that the effects of athleticism are metabolic in nature as opposed to a result of point-of-impact effects. Athleticism and measures of body fat percentage were highly and inversely correlated, further suggesting this may be the case.

\section{Weaknesses}

There are several weaknesses inherent to metaanalyses, and all apply to the present study. First, though all studies that were included in this metaanalysis seemed to be methodologically sound, it is possible that internal biases within some of the studies may be partially influencing the results of the work presented here. ${ }^{32}$ In addition, this smallscale meta-analysis was based on published studies only and so may exclude unpublished studies with null or even opposite findings. However, the studies included in this meta-analysis were derived from 
Table 1. Summary of Included Articles Comparing Bone Mineral Density in Female Athletes and Controls in a Variety of Sports

\begin{tabular}{|c|c|c|c|}
\hline Author & Total Subjects (n) & Study Groups (n) & Summary of Findings \\
\hline Duncan et $\mathrm{al}^{24}$ & 75 & $\begin{array}{l}\text { Cycling (15) } \\
\text { Running (15) } \\
\text { Swimming (15) } \\
\text { Triathletes }(15) \\
\text { Control }(15)\end{array}$ & $\begin{array}{l}\text { Investigated influence of exercise types and differences } \\
\text { in anatomic distribution of mechanical loading } \\
\text { patterns on BMD. Concluded that running is } \\
\text { associated with larger site-specific (Lumbar, Neck, } \\
\text { Legs) BMD than swimming or cycling. Arm } \\
\text { readings also included, which were used for this } \\
\text { review. }\end{array}$ \\
\hline Egan et $\mathrm{al}^{25}$ & 86 & $\begin{array}{l}\text { NetBall }(20) \\
\text { Rugby }(30) \\
\text { Running }(11) \\
\text { Control }(25)\end{array}$ & $\begin{array}{l}\text { All sports groups had higher BMD values than } \\
\text { controls. Upper-body BMD was most pronounced } \\
\text { in rugby players and least pronounced in runners. } \\
\text { Significant correlations between BMD and fat-free } \\
\text { soft tissue mass, body mass, and training volume } \\
\text { were observed. }\end{array}$ \\
\hline Lee et $\mathrm{al}^{14}$ & 62 & $\begin{array}{l}\text { Basketball (7) } \\
\text { Soccer (9) } \\
\text { Swimming (7) } \\
\text { Volleyball (11) } \\
\text { Active control (17) } \\
\text { Nonactive control } \\
(11)\end{array}$ & $\begin{array}{l}\text { Volleyball and basketball athletes had significantly } \\
\text { greater leg and arm measurements than others. All } \\
\text { nonswimmers had significantly greater right arm } \\
\text { measurements relative to swimmers. }\end{array}$ \\
\hline Nichols et $\mathrm{al}^{26}$ & 60 & $\begin{array}{l}\text { Basketball (14) } \\
\text { Gymnastics (15) } \\
\text { Tennis (6) } \\
\text { Volleyball (13) } \\
\text { Control (12) }\end{array}$ & $\begin{array}{l}\text { Examined lean leg mass and regional fat mass as } \\
\text { alternative predictors of } \mathrm{BMD} \text {, and determined lean } \\
\text { leg mass to be a better predictor. Included upper- } \\
\text { arm BMD measurements. }\end{array}$ \\
\hline Trutschnigg et $\mathrm{al}^{23}$ & 44 & $\begin{array}{l}\text { Boxing (11) } \\
\text { Control } 1 \text { (16) } \\
\text { Control } 2 \text { (17) }\end{array}$ & $\begin{array}{l}\text { Goal of the study was to compare relationships } \\
\text { between BMD, lean body mass, fat mass, physical } \\
\text { activity energy expenditure, and menstrual status in } \\
\text { female boxers and physically active females with low } \\
\text { or average fat mass. Boxing (high athleticism) had a } \\
\text { positive effect on BMD. }\end{array}$ \\
\hline Vincente-Rodriguez et $\mathrm{al}^{29}$ & 51 & $\begin{array}{l}\text { Handball (24) } \\
\text { Control (27) }\end{array}$ & $\begin{array}{l}\text { Compared adolescent handballers with controls who } \\
\text { participated only in mandatory physical education, } \\
\text { with no other sports or athletic activity. Found } \\
\text { enhanced axial and appendicular BMD in young } \\
\text { girls who participated in an advanced sporting } \\
\text { activity relative to minimally active controls. }\end{array}$ \\
\hline Taffe \& Marcus ${ }^{27}$ & 40 & $\begin{array}{l}\text { Gymnastics (18) } \\
\text { Control (22) }\end{array}$ & $\begin{array}{l}\text { Examined relationships between BMD and strength in } \\
\text { collegiate women with different exercise levels. } \\
\text { Concluded that association between muscle strength } \\
\text { and BMD in young women is dependent on } \\
\text { exercise status. }\end{array}$ \\
\hline Taffe et $\mathrm{al}^{28}$ & 58 & $\begin{array}{l}\text { Gymnastics (13) } \\
\text { Swimming (26) } \\
\text { Control (19) }\end{array}$ & $\begin{array}{l}\text { Examined the role of skeletal loading patterns on } \\
\text { BMD by comparing eumenorrheic athletes training } \\
\text { by opposite forms of skeletal loading (gymnastics } \\
\text { and swimming, with a nonactive control group). } \\
\text { Gymnasts had higher BMD than swimmers or } \\
\text { controls at several body sites. }\end{array}$ \\
\hline Slemenda \& Johnston ${ }^{30}$ & 44 & $\begin{array}{l}\text { Ice skating (22) } \\
\text { Control }(22)\end{array}$ & $\begin{array}{l}\text { Examined young figure skaters and controls (aged 10- } \\
23 \text { years). Found similar upper-body BMD between } \\
\text { figure skaters and controls, and greater lower-body } \\
\text { BMD in figure skaters. }\end{array}$ \\
\hline Fehling et $\mathrm{al}^{22}$ & 45 & $\begin{array}{l}\text { Gymnastics (13) } \\
\text { Swimming (7) } \\
\text { Volleyball (8) } \\
\text { Control (17) }\end{array}$ & $\begin{array}{l}\text { Compared impact loading with active loading } \\
\text { collegiate athletes and controls. Gymnasts had } \\
\text { significantly greater BMD than all other groups at } \\
\text { right and left arm sites. Impact loading groups had } \\
\text { greater BMD in lower body than the active loading } \\
\text { (swimming) and control groups. No observed } \\
\text { differences between active loading group } \\
\text { (swimming) and control groups. }\end{array}$ \\
\hline
\end{tabular}

BMD, bone mineral density. 
Table 2. Modeling the Effect of Competitive Level of Female Athletes on Bone Mass Density in the Upper Arm of Female Participants Using Weighted Least Squares Linear Regression*

\begin{tabular}{lcc}
\hline Variable & Effect $(\beta)$ & $95 \%$ CI for $\beta$ \\
\hline Elite athleticism $^{\dagger}$ & 0.140 & $0.047-0.234$ \\
Competive $^{\ddagger}$ & 0.010 & -0.095 to 0.115 \\
Active control $^{\S}$ & 0.045 & -0.051 to 0.14 \\
Upper extremity impact $^{\text {II }}$ & 0.037 & -0.025 to 0.099 \\
Age & 0.009 & -0.001 to 0.019 \\
BMI & 0.023 & -0.001 to 0.047 \\
Constant & 0.132 & -0.437 to 0.701 \\
F (p) $=6.353(P<.000)$ & $\mathrm{R}^{2}=0.536$ & \\
\hline
\end{tabular}

*The $\beta$ coefficient indicates the estimated effect size of each variable. The model indicates that elite athleticism, defined as participation in Division I-level competitive sport at the time of measurement, significantly predicts an increase of bone mass density in the upper arm by $0.140 \mathrm{~g} / \mathrm{cm}^{-2}$, when age, impact level of sport, and body mass index are controlled. Each variable was entered as the mean for each study group.

${ }^{\dagger}$ Elite athletes included NCAA Division I competitors.

${ }^{\ddagger}$ Competitive collegiate athletes included NCAA Division II or III competitors.

${ }^{\S}$ Noncompetitive athletes, eg, joggers, noncompetitive swimmers, and intramurals.

"Basketball, boxing, gymnastics, handball, and volleyball $=1$ versus 0 for low impact and control.

BMI, body mass index.

a larger, ongoing effort to qualitatively review the literature on links between BMD and elite athleticism. To this point, we have not found any evidence of unpublished work that would lead to conclusions opposite of those presented here. Another weakness of this study is our focus on only upper-extremity BMD. This focus allowed for a more uniform comparison of effects, but it is possible that the results we report here may not generalize to other body sites. A related issue is that there may be differences between BMD in the dominant versus nondominant arm. Not all studies reported whether BMD readings were taken in dominant arms, so it was not possible to control for this issue.

It is of great importance to note that although this meta-analysis has demonstrated an association between increasing BMD and increasing level of competition (and, assumedly, of the intensity of the conditioning), it does not demonstrate or suggest causality. It is possible, for instance, that individuals with metabolic predispositions toward higher $\mathrm{BMD}$ tend to fare better in athletic competition.

\section{Conclusions}

Further primary research can be done to evaluate the minimal competitive participation that stimulates significant BMD accretion. This deduction can be done across multiple sports and can be applied to other female athlete profiles, such as adolescent and postmenopausal groups and women with established comorbidities.

Presently, however, the results of this metaanalysis suggest that clinicians may see iteratively greater BMD in young adult female patients who compete at increasingly intense collegiate athletic levels, with elite athletes having BMD measurements that are much higher than other patients, whether they are active or not. This runs counter to some recent findings, indicating lower rates of bone accretion in some athletes. In addition, the effect of increased BMD may be far more dependent on the intensity level of athletic participation as opposed to the type of sport or the impact of particular sport choices on specific parts of the body.

We are grateful to comments provided by Dr. John Epling in response to a draft of this manuscript.

\section{References}

1. Flawn LB. Amenorrhea, anorexia, and osteoporosis- the female triad. Curr Opin Orthop 1994;5(5):16-20.

2. Guadalupe-Grau A, Fuentes T, Guerra B, Calbet JA. Exercise and bone mass in adults. Sports Med 2009; 39(6):439-68.

3. Revel M, Mayoux-Benhamou MA, Rabourdin JP, Bagheri F, Roux C. One-year psoas training can prevent lumbar bone loss in postmenopausal women: a randomized controlled trial. Calcif Tissue Int 1993;53(5):307-11.

4. Burr DB, Robling AG, Turner CH. Effects of biomechanical stress on bones in animals. Bone 2002; 30(5):781-6.

5. Kohrt WM, Bloomfield SA, Little KD, Nelson ME, Yingling VR, American College of Sports Medicine. American College of Sports Medicine Position Stand: physical activity and bone health. Med Sci Sports Exerc 2004;36(11):1985-96.

6. Taaffe DR, Robinson TL, Snow CM, Marcus R. High-impact exercise promotes bone gain in welltrained female athletes. J Bone Miner Res 1997; 12(2):255-60.

7. Fuchs RK, Bauer JJ, Snow CM. Jumping improves hip and lumbar spine bone mass in prepubescent children: a randomized controlled trial. J Bone Miner Res 2001;16(1):148-56.

8. MacKelvie KJ, McKay HA, Petit MA, Moran O, Khan KM. Bone mineral response to a 7-month 
randomized controlled, school-based jumping intervention in 121 prepubertal boys: associations with ethnicity and body mass index. J Bone Miner Res 2002;17(5):834-44.

9. MacKelvie KJ, Khan KM, Petit MA, Janssen PA, McKay HA. A school-based exercise intervention elicits substantial bone health benefits: a 2-year randomized controlled trial in girls. Pediatrics 2003; 112(6 Pt 1):e447.

10. McKay HA, Petit MA, Schutz RW, Prior JC, Barr SI, Khan KM. Augmented trochanteric bone mineral density after modified physical education classes: a randomized school-based exercise intervention study in prepubescent and early pubescent children. $\mathrm{J} \mathrm{Pe-}$ diatr 2000;136(2):156-62.

11. Bareither ML, Grabiner MD, Troy KL. Habitual site-specific upper extremity loading is associated with increased bone mineral of the ultradistal radius in young women. J Womens Health (Larchmt) 2008; 17(10):1577-81.

12. Alfredson H, Nordstrom P, Lorentzon R. Total and regional bone mass in female soccer players. Calcif Tissue Int 1996;59(6):438-42.

13. Alfredson H, Nordstrom P, Lorentzon R. Bone mass in female volleyball players: a comparison of total and regional bone mass in female volleyball players and nonactive females. Calcif Tissue Int 1997;60(4): $338-42$.

14. Lee EJ, Long KA, Risser WL, Poindexter HB, Gibbons WE, Goldzieher J. Variations in bone status of contralateral and regional sites in young athletic women. Med Sci Sports Exerc 1995;27(10):1354-61.

15. Nattiv A, Loucks AB, Manore MM, et al. American College of Sports Medicine position stand. The female athlete triad. Med Sci Sports Exerc 2007; 39(10):1867-82.

16. Madsen OR, Schaadt O, Bliddal H, Egsmose C, Sylvest J. Relationship between quadriceps strength and bone mineral density of the proximal tibia and distal forearm in women. J Bone Miner Res 1993; 8(12):1439-44.

17. Loucks AB. Effects of exercise training on the menstrual cycle: existence and mechanisms. Med Sci Sports Exerc 1990;22(3):275-80.

18. Moher D, Liberati A, Tetzlaff J, Altman DG, PRISMA Group. Preferred reporting items for systematic reviews and meta-analyses: the PRISMA statement. PLoS Med 2009;6(7):e1000097.

19. Maimoun L, Coste O, Galtier F, et al. Bone mineral density acquisition in peripubertal female rhythmic gymnasts is directly associated with plasma IGF1/ IGF-binding protein 3 ratio. Eur J Endocrinol 2010; 163(1):157-64.
20. Torstveit MK, Sundgot-Borgen J. Low bone mineral density is two to three times more prevalent in nonathletic premenopausal women than in elite athletes: a comprehensive controlled study. Br J Sports Med 2005;39(5):282-7, discussion 282-7.

21. NCAA [homepage]. Available at: http://www.ncaa. org/. Accessed 11 October 2011.

22. Fehling PC, Alekel L, Clasey J, Rector A, Stillman RJ. A comparison of bone mineral densities among female athletes in impact loading and active loading sports. Bone 1995;17(3):205-10.

23. Trutschnigg B, Chong C, Habermayerova L, Karelis $\mathrm{AD}$, Komorowski J. Female boxers have high bone mineral density despite low body fat mass, high energy expenditure, and a high incidence of oligomenorrhea. Appl Physiol Nutr Metab 2008;33(5): 863-9.

24. Duncan CS, Blimkie CJ, Cowell CT, Burke ST, Briody JN, Howman-Giles R. Bone mineral density in adolescent female athletes: relationship to exercise type and muscle strength. Med Sci Sports Exerc 2002;34(2):286-94.

25. Egan E, Reilly T, Giacomoni M, Redmond L, Turner C. Bone mineral density among female sports participants. Bone 2006;38(2):227-33.

26. Nichols JF, Rauh MJ, Barrack MT, Barkai HS. Bone mineral density in female high school athletes: interactions of menstrual function and type of mechanical loading. Bone 2007;41(3):371-7.

27. Taaffe DR, Marcus R. The muscle strength and bone density relationship in young women: dependence on exercise status. J Sports Med Phys Fitness 2004;44(1):98-103.

28. Taaffe DR, Snow-Harter C, Connolly DA, Robinson TL, Brown MD, Marcus R. Differential effects of swimming versus weight-bearing activity on bone mineral status of eumenorrheic athletes. J Bone Miner Res 1995;10(4):586-93.

29. Vicente-Rodriguez G, Dorado C, Perez-Gomez J, Gonzalez-Henriquez JJ, Calbet JA. Enhanced bone mass and physical fitness in young female handball players. Bone 2004;35(5):1208-15.

30. Slemenda CW, Johnston CC. High intensity activities in young women: site specific bone mass effects among female figure skaters. Bone Miner 1993; 20(2):125-32.

31. Nichols DL, Sanborn CF, Bonnick SL, Gench B, DiMarco N. Relationship of regional body composition to bone mineral density in college females. Med Sci Sports Exerc 1995;27(2):178-82.

32. Slavin RE. Best-evidence synthesis: an alternative to meta-analytic and traditional reviews. Educational Researcher 1986;15(9):5-11. 